\title{
Palladium-Mediated Polymerization of Bifunctional Diazocarbonyl Compounds: Preparation of Crosslinked Polymers by Copolymerization of Bi- and Monofunctional Diazocarbonyl Compounds
}

\author{
By Eiji IHARA, ${ }^{*}$ Yuko Goto, Tomomichi ITOH, and Kenzo INOUE*
}

Pd-mediated copolymerization of bifunctional diazocarbonyl compounds, 1,1'-bis(diazoacetyl)ferrocene 2, 4,4'-bis(diazoacetyl)biphenyl 5, and bis(4-diazoacetylphenyl)dimethylsilane 6, with monofunctional diazoketones, (E)-1-diazo-3-nonen-2one 3 and $(E)$-1-diazo-4-phenyl-3-buten-2-one 4, and ethyl diazoacetate 7 was examined in order to prepare a new type of crosslinked polymer. Although copolymerization of $\mathbf{2}$ with 3 and 4 proceeded in the presence of $\mathrm{PdCl}_{2}\left(\mathrm{MeCN}_{2}\right.$, the products were soluble in $\mathrm{CHCl}_{3}$ and their $M_{\mathrm{n}} \mathrm{s}$ were rather low irrespective of the feed ratio of the comonomers, probably because of the occurrence of intramolecular cyclization of two diazoacetyl groups in 2. On the other hand, copolymerization of 5 and $\mathbf{6}$ with $3, \mathbf{4}$, and 7 with relatively high feed ratios of the bifunctional monomers afforded products insoluble in $\mathrm{CHCl}_{3}$, which suggested the formation of crosslinked polymers. In addition, Pd-mediated (co)polymerization of monofunctional diazoacetylferrocene $\mathbf{1}$, monofunctional counterpart to 2 , was examined, resulting in the formation of a new type of ferrocene-containing polymer.

KEY WORDS: Copolymerization / Crosslinking / Network Polymer / Bis(diazocarbonyl) Compound /

Recently, we and other groups have been developing polymerization of diazocarbonyl compounds, that can afford a new type of $\mathrm{C}-\mathrm{C}$ main chain polymer bearing carbonylcontaining substitutents on its all the main chain carbon atoms. $\mathrm{Cu}-,{ }^{1} \mathrm{Pd}-{ }^{2}$ Rh-, ${ }^{3,4}$ and B-mediated ${ }^{5}$ polymerization and oligomerization have been reported for alkyl diazoacetate, which is the most common type of diazocarbonyl compound. ${ }^{6}$ In addition, we have reported Pd-mediated polymerization of diazoketone $^{7,8}$ and diazoacetamide, ${ }^{9}$ which can afford poly(acylmethylene) and poly( $N$-substituted carbamoylmethylene), respectively, to extend the utility of the polymerization as a general method for polymer synthesis.

On the other hand, although polymerization of bifunctional diazocarbonyl compounds [bis(diazocarbonyl) compounds] has not been reported so far, polymerization of such compounds would be able to afford a new type of crosslinked polymer (network polymer). For example, copolymerization of bi- and monofunctional diazocarbonyl compounds would result in the formation of crosslinked polymers, which should have higher density of substituent (functional group) in each lattice in the network than analogous polymers obtained by conventional vinyl polymerization, because polymers derived from diazocarbonyl compounds should have closer packing of substitutents along their main chains compared to those obtained from vinyl polymerization. Thus, we might be able to establish a new method for preparing network polymers, comparable to the copolymerization of styrene with divinylbenzene, which has been recognized as a very useful method and utilized for various applications such as synthesis of a variety of ion-exchange resins.

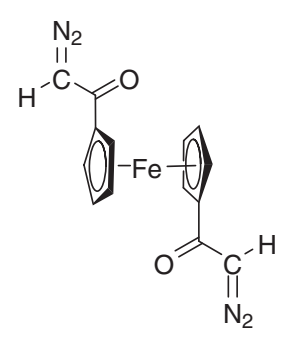

2 5<smiles>N#CC(=O)c1ccc(-c2ccc(C(=O)C=[W])cc2)cc1</smiles>

5<smiles>C[Si](C)(c1ccc(C(=O)C=N)cc1)c1ccc(C(=O)C=N)cc1</smiles>

6
Scheme 1. Bifunctional diazocarbonyl compounds employed in this study.

In this paper, as such bis(diazocarbonyl) compounds, we chose 1,1'-bis(diazoacetyl)ferrocene 2, 4,4'-bis(diazoacetyl)biphenyl 5, and bis(4-diazoacetylphenyl)dimethylsilane $\mathbf{6}$ (Scheme 1), and investigated their reactivity for Pd-mediated polymerization, particularly focusing on the copolymerization with monofunctional diazoketones and ethyl diazoacetate in order to prepare crosslinked polymers.

\section{EXPERIMENTAL}

\section{Materials}

Toluene and THF were dried over sodium and $\mathrm{Na} / \mathrm{K}$ alloy, respectively, and distilled before use. 1,1,1,3,3,3-hexamethyl- 
disilazane (TCI, >96\%) and 2,2,2-trifluoroethyl trifluoroacetate (Aldrich, 99\%) were dried over $\mathrm{CaH}_{2}$ and used without further purification. $n$-BuLi (Kanto Chemical, $1.57 \mathrm{M}$ in $n$ hexane) was used as received. Though commercially available, 4,4'-bis(acetyl)biphenyl was prepared by Pd-catalyzed homocoupling of Grignard reagent derived from carbonyl-protected 1-acetyl-4-bromobenzene. Bis(4-acetylpheny)dimethylsilane ${ }^{12}$ was prepared by the reaction of the above Grignard reagent with $\mathrm{Me}_{2} \mathrm{SiCl}_{2}$. Diazoacetylferrocene ${ }^{10}$ and 1,1'-bis(diazoacetyl)ferrocene ${ }^{11}$ were prepared by diazo-transfer reaction employed for the synthesis of $\mathbf{5}$ and $\mathbf{6}$, of acetylferrocene and 1,1'diazoacetylferrocene, respectively. Methanesulfonyl azide, ${ }^{13}$ diazoketone monomers $\mathbf{3},{ }^{7} \mathbf{4},{ }^{13}$ ethyl diazoacetate $\mathbf{7},{ }^{14}$ and $\mathrm{PdCl}_{2}(\mathrm{MeCN})_{2},{ }^{15}$ were prepared according to the literatures.

\section{Measurements}

${ }^{1} \mathrm{H}(400 \mathrm{MHz})$ and ${ }^{13} \mathrm{C}(100 \mathrm{MHz})$ NMR spectra were recorded on a Bruker Avance 400 spectrometer using tetramethysilane as an internal standard in chloroform- $d\left(\mathrm{CDCl}_{3}\right)$ or dimethyl sulfoxide (DMSO)- $d_{6}$ at room temperature (monomers) or at $50{ }^{\circ} \mathrm{C}$ (polymers).

Molecular weights $\left(M_{\mathrm{n}}\right)$ and molecular weight distributions $\left(M_{\mathrm{w}} / M_{\mathrm{n}}\right)$ were measured by means of gel permeation chromatography (GPC) on a Jasco-ChromNAV system equipped with a differential refractometer detector using tetrahydrofuran as eluent at a flow rate of $1.0 \mathrm{~mL} / \mathrm{min}$ at $40^{\circ} \mathrm{C}$, calibrated with poly(MMA). The column used for the GPC analyses was a combination of Styragel HR4 (Waters; $300 \mathrm{~mm} \times 7.8 \mathrm{~mm}$ i.d., $5 \mu \mathrm{m}$ average particle size, exclusion molecular weight of $600 \mathrm{~K}$ for polystyrene) and Styragel HR2 (Waters; $300 \mathrm{~mm} \times$ $7.8 \mathrm{~mm}$ i.d., $5 \mu \mathrm{m}$ average particle size, exclusion molecular weight of $20 \mathrm{~K}$ for polystyrene), and poly(MMA) standards (Shodex M-75, $M_{\mathrm{n}}=200000, M_{\mathrm{w}} / M_{\mathrm{n}}=1.05, M_{\mathrm{n}}=47300$, $M_{\mathrm{w}} / M_{\mathrm{n}}=1.02, \quad M_{\mathrm{n}}=21700, \quad M_{\mathrm{w}} / M_{\mathrm{n}}=1.02, \quad M_{\mathrm{n}}=5220$, $\left.M_{\mathrm{w}} / M_{\mathrm{n}}=1.06, \quad M_{\mathrm{n}}=2190, \quad M_{\mathrm{w}} / M_{\mathrm{n}}=1.08\right)$ and dibutyl sebacate $(\mathrm{MW}=314.5)$ were used for the calibration. For the sample obtained in run 6 in Table II, calibration was carried out with poly(MMA) standards (Shodex M-75, $M_{\mathrm{n}}=$ 2190-653000, $\left.M_{\mathrm{w}} / M_{\mathrm{n}}=1.03-1.08\right)$, and the column used for the GPC analyses was a combination of $\mathrm{G}^{2} 000 \mathrm{H}_{\mathrm{HR}}(\mathrm{TOSOH}$; $300 \mathrm{~mm} \times 7.8 \mathrm{~mm}$ i.d., $5 \mu \mathrm{m}$ average particle size, exclusion molecular weight of $4000 \mathrm{~K}$ for polystyrene), $\mathrm{G} 4000 \mathrm{H}_{\mathrm{HR}}$ (TOSOH; $300 \mathrm{~mm} \times 7.8 \mathrm{~mm}$ i.d., $5 \mu \mathrm{m}$ average particle size, exclusion molecular weight of $400 \mathrm{~K}$ for polystyrene), and $\mathrm{G} 3000 \mathrm{H}_{\mathrm{HR}}$ (TOSOH; $300 \mathrm{~mm} \times 7.8 \mathrm{~mm}$ i.d., $5 \mu \mathrm{m}$ average particle size, exclusion molecular weight of $60 \mathrm{~K}$ for polystyrene).

Purification by preparative recycling GPC was performed on a JAI LC-918R equipped with a combination of columns of a JAIGEL-3H $(600 \mathrm{~mm} \times 20 \mathrm{~mm}$ i.d., exclusion molecular weight of $70 \mathrm{~K}$ for polystyrene) and a JAIGEL-2H $(600 \mathrm{~mm} \times$ $20 \mathrm{~mm}$ i.d., exclusion molecular weight of $20 \mathrm{~K}$ for polystyrene) using $\mathrm{CHCl}_{3}$ as eluent at a flow rate of $3.8 \mathrm{~mL} / \mathrm{min}$ at $25^{\circ} \mathrm{C}$. The sample solution $(3 \mathrm{~mL}$ containing $c a .0 .3 \mathrm{~g}$ of the crude product) was injected and recycled before fractionation.
Thermogravimetric analyses of the polymers were carried out using a Seiko TG/DTA 6200, under nitrogen atmosphere at a $10^{\circ} \mathrm{C} / \mathrm{min}$ heating rate.

Elemental analyses were performed on a YANAKO MT-5 analyzer at Integrated Center for Science (INCS) in Ehime University.

\section{Preparation of $4, \mathbf{4}^{\prime}$-Bis(diazoacetyl)biphenyl 5}

Under a $\mathrm{N}_{2}$ atmosphere, a THF $(35 \mathrm{~mL})$ solution of 1,1,1,3,3,3-hexamethyldisilazane $(8.0 \mathrm{~mL}, \quad 38 \mathrm{mmol})$ was placed in a round-bottomed flask equipped with a dropping funnel and a three-way stopcock, and the solution was cooled to $0{ }^{\circ} \mathrm{C}$. After $n$-BuLi ( $1.57 \mathrm{M}$ in hexane, $24.0 \mathrm{~mL}, 37.8 \mathrm{mmol}$ ) was added to the solution and the mixture was stirred at $0{ }^{\circ} \mathrm{C}$ for $10 \mathrm{~min}$., it was cooled to $-78^{\circ} \mathrm{C}$. From the dropping funnel, a THF $(80 \mathrm{~mL})$ solution of 4,4'-diacetylbiphenyl $(3.00 \mathrm{~g}, 12.6$ mmol) was added to the mixture dropwise for $15 \mathrm{~min}$., and the mixture was stirred for $30 \mathrm{~min}$. at $-78^{\circ} \mathrm{C}$. After $2,2,2-$ trifluoroethyl trifluoroacetate $(6.0 \mathrm{~mL}, 44 \mathrm{mmol})$ was added to the mixture by using a syringe, the resulting mixture was stirred for $10 \mathrm{~min}$. at $-78^{\circ} \mathrm{C}$. Then, the mixture was gradually warmed to room temperature, and diethyl ether $(50 \mathrm{~mL})$ and $1.0 \mathrm{~N}$ aqueous $\mathrm{HCl}(100 \mathrm{~mL})$ were added to it. The organic layer was separated using separatory funnel, and the aqueous layer was extracted with $50 \mathrm{~mL}$ of diethyl ether. After the combined organic layer was washed with saturated $\mathrm{NaCl}$ aqueous solution $(100 \mathrm{~mL})$ and dried over $\mathrm{Na}_{2} \mathrm{SO}_{4}$, volatiles were removed under reduced pressure to give a pale yellow solid, which was dissolved into $90 \mathrm{~mL}$ of acetonitrile. The solution was placed in a round-bottomed flask equipped with a dropping funnel and a three-way stopcock, and water $(0.45 \mathrm{~mL}$, $25 \mathrm{mmol})$ and triethylamine $(5.25 \mathrm{~mL}, 37.8 \mathrm{mmol})$ were added to the solution. After the mixture was stirred for $10 \mathrm{~min}$. at room temperature, an acetonitrile $(20 \mathrm{~mL})$ solution of methanesulfonyl azide $(4.57 \mathrm{~g}, 37.8 \mathrm{mmol})$ was added to the mixture from the dropping funnel dropwise for $20 \mathrm{~min}$., the resulting mixture was stirred at room temperature for $6 \mathrm{~h}$. After diethyl ether $(50 \mathrm{~mL})$ and $5 \% \mathrm{NaOH}$ aqueous solution $(100 \mathrm{~mL})$ were added, the organic layer was separated, washed with $100 \mathrm{~mL}$ of saturated $\mathrm{NaCl}$ aqueous solution, dried over $\mathrm{Na}_{2} \mathrm{SO}_{4}$. Volatiles were removed under reduced pressure to afford a pale yellow solid, which was purified by removing impurity soluble in ethyl acetate. 4,4'-Bis(diazoacetyl)biphenyl (1.20 g, $4.14 \mathrm{mmol})$ was obtained in a $32.9 \%$ yield as a pale yellow solid.

${ }^{1} \mathrm{H}$ NMR $\left(400 \mathrm{MHz},\left(\mathrm{CD}_{3}\right)_{2} \mathrm{SO}\right) \delta 7.97(\mathrm{~d}, J=8.4 \mathrm{~Hz}, 4 \mathrm{H}$, $\operatorname{Ar}-\mathrm{H}), 7.90$ (d, $J=8.4 \mathrm{~Hz}, 4 \mathrm{H}, \mathrm{Ar}-\mathrm{H}), 7.05$ (s, 2H, $\mathrm{N}_{2} \mathrm{CH}-$ ); ${ }^{13} \mathrm{C} \mathrm{NMR}\left(100 \mathrm{MHz},\left(\mathrm{CD}_{3}\right)_{2} \mathrm{SO}\right) \delta 158.4(\mathrm{C}=\mathrm{O}), 116.1(\mathrm{Ar})$, 108.9 (Ar), 100.6 (Ar), 100.5 (Ar), $27.4\left(\mathrm{~N}_{2} \mathrm{CH}-\right)$. Anal. Calcd for $\mathrm{C}_{16} \mathrm{H}_{10} \mathrm{~N}_{4} \mathrm{O}_{2} \cdot 0.3 \mathrm{H}_{2} \mathrm{O}$ : C, 64.99; $\mathrm{H}, 3.61 ; \mathrm{N}, 18.95$. Found: C, 65.03; H, 3.47; N, 17.91 .

Bis(4-diazoacetylphenyl)dimethylsilane 6 was prepared in a similar manner from bis(4-acetylpheny)dimethylsilane. A pale yellow solid was obtained in a $78.8 \%$ yield.

${ }^{1} \mathrm{H}$ NMR $\left(400 \mathrm{MHz},\left(\mathrm{CDCl}_{3}\right) \delta 7.73(\mathrm{~d}, J=8.0 \mathrm{~Hz}, 4 \mathrm{H}, \mathrm{Ar}-\right.$ $\mathrm{H}), 7.59(\mathrm{~d}, J=7.6 \mathrm{~Hz}, 4 \mathrm{H}, \operatorname{Ar}-\mathrm{H}), 5.91$ (s, 2H, $\left.\mathrm{N}_{2} \mathrm{CH}-\right)$; ${ }^{13} \mathrm{C}$ NMR $\left(100 \mathrm{MHz},\left(\mathrm{CDCl}_{3}\right) \delta 189.0(\mathrm{C}=\mathrm{O}), 146.2(\mathrm{Ar})\right.$, 
140.0 (Ar), 137.2 (Ar), $128.6(\mathrm{Ar}), 57.1\left(\mathrm{~N}_{2} \mathrm{CH}-\right), 0.0\left(\mathrm{SiCH}_{3}\right)$. Anal. Calcd for $\mathrm{C}_{18} \mathrm{H}_{16} \mathrm{~N}_{4} \mathrm{O}_{2} \mathrm{Si} \cdot 0.09 \mathrm{H}_{2} \mathrm{O}: \mathrm{C}, 61.76 ; \mathrm{H}, 4.66 ; \mathrm{N}$, 16.01. Found: C, 62.05; H, 4.63; N, 16.08.

\section{Polymerization Procedure}

As a typical procedure, copolymerization of $\mathbf{6}$ with $\mathbf{3}$ was described as follows.

Under a $\mathrm{N}_{2}$ atmosphere, $\mathrm{PdCl}_{2}(\mathrm{MeCN})_{2}(4.5 \mathrm{mg}, 0.0172$ $\mathrm{mmol})$ and $6(50.0 \mathrm{mg}, 0.144 \mathrm{mmol})$ were placed in a Schlenk tube. After a toluene $(4.3 \mathrm{~mL})$ solution of $3(119.0 \mathrm{mg}, 0.718$ mmol) was added, the mixture was stirred at $50{ }^{\circ} \mathrm{C}$ for $17 \mathrm{~h}$. After the volatiles were removed under reduced pressure, a $\mathrm{MeOH}$ solution of $\mathrm{HCl}(1 \mathrm{~N}, 10 \mathrm{~mL})$, aqueous solution of $\mathrm{HCl}$ ( $1 \mathrm{~N}, 10 \mathrm{~mL})$, and $\mathrm{CHCl}_{3}(20 \mathrm{~mL})$ were added to the residue. The organic layer was extracted with a separatory funnel, and the aqueous layer was extracted with $30 \mathrm{~mL}$ of $\mathrm{CHCl}_{3}$. The combined organic layer was washed with $50 \mathrm{~mL}$ of $1 \mathrm{~N}$ aqueous solution of $\mathrm{HCl}$ and $50 \mathrm{~mL}$ of water, dried over $\mathrm{Na}_{2} \mathrm{SO}_{4}$. The solid obtained after removal of volatiles under reduced pressure was purified by using preparative recycling GPC to give a polymer as a reddish-brown solid $(70.6 \mathrm{mg}$, $47.8 \%)$.

Other Pd-mediated polymerization of diazocarbonyl compounds were carried out in a similar procedure. When the residue obtained after polymerization was insoluble to $\mathrm{CHCl}_{3}$, it was thoroughly washed with $1 \mathrm{~N}$ aqueous solution of $\mathrm{HCl}$ and water, and dried under reduced pressure.

Poly1': ${ }^{1} \mathrm{H}$ NMR $\left(400 \mathrm{MHz}, \mathrm{CDCl}_{3}\right) \delta$ 4.4-5.4 (-[CO]C ${ }_{5} \mathrm{H}_{4}-$ Fe-), 4.3-4.7 (-[CO]C $\left.\mathrm{H}_{4}-\mathrm{Fe}-\right)$, 3.8-4.5 ( $\left.\mathrm{C}_{5} \mathrm{H}_{5}-\mathrm{Fe}-\right), 2.8-3.8$ (main chain $\mathrm{CH})$. Poly $\left(\mathbf{1}^{\prime}-\mathrm{co}-\mathbf{3}^{\prime}\right)$ : ${ }^{1} \mathrm{H}$ NMR $\left(400 \mathrm{MHz}, \mathrm{CDCl}_{3}\right)$ $\delta$ 5.8-7.2 $(-[\mathrm{CO}] \mathrm{CH}=\mathrm{CH}-), 4.2-5.3\left(-[\mathrm{CO}] \mathrm{C}_{5} \mathrm{H}_{4}-\mathrm{Fe}-\right), 4.2-4.9$ $\left(-[\mathrm{CO}] \mathrm{C}_{5} \mathrm{H}_{4}-\mathrm{Fe}-\right), 3.8-4.5 \quad\left(\mathrm{C}_{5} \mathrm{H}_{5}-\mathrm{Fe}-\right), \quad 1.9-2.5 \quad(-\mathrm{CH}=\mathrm{CH}-$ $\mathrm{CH}_{2}{ }^{-}$), 3.0-4.0 (main chain $\left.\mathrm{CH}\right), 0.9-1.9\left(-\left[\mathrm{CH}_{2}\right]_{3}-\right), 0.4-1.2$ $\left(-\mathrm{CH}_{3}\right)$. Poly $\left(\mathbf{1}^{\prime}-\mathrm{co}-\mathbf{4}^{\prime}\right):{ }^{1} \mathrm{H} \mathrm{NMR}\left(400 \mathrm{MHz}, \mathrm{CDCl}_{3}\right) \delta 6.6-8.2$ $\left(-\mathrm{CH}=\mathrm{CH}-\mathrm{C}_{6} \mathrm{H}_{5}\right), 4.4-5.3 \quad\left(-[\mathrm{CO}] \mathrm{C}_{5} \mathrm{H}_{4}-\mathrm{Fe}-\right), 4.1-4.8$ (-[CO]$\left.\mathrm{C}_{5} \mathrm{H}_{4}-\mathrm{Fe}-\right)$, 3.6-4.5 $\left(\mathrm{C}_{5} \mathrm{H}_{5}-\mathrm{Fe}-\right)$, 3.0-4.0 (main chain $\mathrm{CH}$ ). $\operatorname{Poly}\left(\mathbf{2}^{\prime}-\mathrm{co}-\mathbf{3}^{\prime}\right): \quad{ }^{1} \mathrm{H} \mathrm{NMR} \quad\left(400 \mathrm{MHz}, \quad \mathrm{CDCl}_{3}\right) \quad \delta \quad 5.6-7.8$ $(-[\mathrm{CO}] \mathrm{C} H=\mathrm{CH}-), \quad 3.9-5.4 \quad\left(-[\mathrm{CO}] \mathrm{C}_{5} H_{4}-\mathrm{Fe}-\mathrm{C}_{5} H_{5}\right), \quad 2.8-3.8$ (main chain $\mathrm{CH}$ ), 2.0-2.4 $\quad\left(-\mathrm{CH}=\mathrm{CH}_{-} \mathrm{CH}_{2}-\right), \quad 1.0-2.0$ $\left(-\left[\mathrm{CH}_{2}\right]_{3}-\right), 0.5-1.1 \quad\left(-\mathrm{CH}_{3}\right)$. Poly $\left(\mathbf{2}^{\prime}-\mathrm{co}^{-} \mathbf{4}^{\prime}\right):{ }^{1} \mathrm{H}$ NMR (400

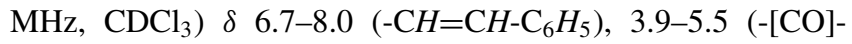
$\mathrm{C}_{5} \mathrm{H}_{4}-\mathrm{Fe}-\mathrm{C}_{5} \mathrm{H}_{5}$ ), 3.0-4.0 (main chain $\mathrm{CH}$ ). Poly $\left(\mathbf{3}^{\prime}-\mathrm{co}^{-} \mathbf{5}^{\prime}\right)$ : ${ }^{1} \mathrm{H}$ NMR $\left(400 \mathrm{MHz}, \mathrm{CDCl}_{3}\right) \quad \delta \quad 7.7-8.4 \quad\left(-\mathrm{C}_{6} \mathrm{H}_{4}-\right), \quad 7.3-7.9$ $\left(-\mathrm{C}_{6} \mathrm{H}_{4}-\right)$, 5.6-7.2 (-[CO]CH=CH-), 3.0-4.0 (main chain $\left.\mathrm{CH}\right)$, 2.0-2.4 (-CH=CH-CH $\left.2_{2}^{-}\right), 1.3-1.8\left(-\left[\mathrm{CH}_{2}\right]_{3}-\right), 0.5-1.3\left(-\mathrm{CH}_{3}\right)$. $\operatorname{Poly}\left(\mathbf{5}^{\prime}-\mathrm{co}-\mathbf{7}^{\prime}\right):{ }^{1} \mathrm{H} \mathrm{NMR}\left(400 \mathrm{MHz}, \mathrm{CDCl}_{3}\right) \delta$ 7.7-8.4 $\left(-\mathrm{C}_{6} \mathrm{H}_{4}-\right)$, 7.1-8.0 (- $\left.\mathrm{C}_{6} \mathrm{H}_{4}-\right)$, 3.6-4.6 (-O- $\left.\left[\mathrm{CH}_{2}\right]-\right)$, 3.0-3.9 (main chain $\mathrm{CH}), \quad 0.6-1.6 \quad\left(-\mathrm{CH}_{3}\right)$. Poly $\left(3^{\prime}-\mathrm{co}-\mathbf{6}^{\prime}\right):{ }^{1} \mathrm{H} \mathrm{NMR}(400 \mathrm{MHz}$, $\left.\mathrm{CDCl}_{3}\right) \quad \delta \quad 7.7-8.2 \quad\left(-\mathrm{C}_{6} \mathrm{H}_{4}-\mathrm{Si}\left[\mathrm{CH}_{3}\right]_{2}-\right), 6.7-7.8 \quad\left(-\mathrm{C}_{6} \mathrm{H}_{4}-\right.$ $\left.\mathrm{Si}\left[\mathrm{CH}_{3}\right]_{2}-\right), \quad 5.1-6.7 \quad(-[\mathrm{CO}] \mathrm{CH}=\mathrm{CH}-), \quad 1.8-2.4 \quad(-\mathrm{CH}=\mathrm{CH}-$ $\left.\mathrm{CH}_{2}-\right), \quad 0.8-1.8 \quad\left(-\left[\mathrm{CH}_{2}\right]_{3}-\right), \quad 0.7-1.0 \quad\left(-\mathrm{CH}_{3}\right) \quad 0.2-0.9$ $\left(-\mathrm{Si}\left[\mathrm{CH}_{3}\right]_{2}-\right)$. Signals for main chain $\mathrm{CH}$ could not be identified. Poly $\left(4^{\prime}-\right.$ co-6 $\left.^{\prime}\right):{ }^{1} \mathrm{H}$ NMR $\left(400 \mathrm{MHz}, \mathrm{CDCl}_{3}\right) \delta 7.6-$ $8.3 \quad\left(-\mathrm{C}_{6} \mathrm{H}_{4}-\mathrm{Si}\left[\mathrm{CH}_{3}\right]_{2}-\right), 7.3-7.9 \quad\left(-\mathrm{C}_{6} \mathrm{H}_{4}-\mathrm{Si}\left[\mathrm{CH}_{3}\right]_{2}-\right), 6.3-7.8$ $\left(-\mathrm{CH}=\mathrm{CH}-\mathrm{C}_{6} \mathrm{H}_{5}\right), \quad 3.0-4.0$ (main chain $\mathrm{CH}$ ), 0.2-0.7 $\left(-\mathrm{Si}\left[\mathrm{CH}_{3}\right]_{2}-\right)$. Poly $\left(6^{\prime}-\mathrm{co}-\mathbf{7}^{\prime}\right)$ : ${ }^{1} \mathrm{H} \mathrm{NMR}\left(400 \mathrm{MHz}, \mathrm{CDCl}_{3}\right) \delta$
7.7-8.2 (- $\left.\mathrm{C}_{6} \mathrm{H}_{4}-\mathrm{Si}\left[\mathrm{CH}_{3}\right]_{2}\right), 6.9-7.8\left(-\mathrm{C}_{6} \mathrm{H}_{4}-\mathrm{Si}\left[\mathrm{CH}_{3}\right]_{2}\right), 3.9-4.5$ (-O-[CH $\left(-\mathrm{Si}\left[\mathrm{CH}_{3}\right]_{2}-\right)$. All peaks appeared as very broad signals.

\section{RESULTS AND DISCUSSION}

\section{Pd-mediated Polymerization of Diazoacetylferrocene (1)} and $1, \mathbf{1}^{\prime}$-Bis(diazoacetyl)ferrocene (2)

As a bifunctional diazocarbonyl compound which can be used for the synthesis of network polymers, we first chose $1,1^{\prime}$ bis(diazoacetyl)ferrocene (2). In order to check the reactivity of the diazoacetyl group of $\mathbf{2}$, we also examined the Pd-mediated polymerization of diazoacetylferrocene $\mathbf{1}$, monofunctional counterpart to $\mathbf{2}$. These diazoacetyl-substituted ferrocenes $\mathbf{1}^{10}$ and $\mathbf{2}^{11}$ are reported compounds and can be prepared from the corresponding acetylferrocene derivatives.

When 1 was reacted with $\mathrm{PdCl}_{2}(\mathrm{MeCN})_{2}$ in a feed ratio of $[1] /\left[\mathrm{PdCl}_{2}(\mathrm{MeCN})_{2}\right]=100: 3.5$ at $50{ }^{\circ} \mathrm{C}$ in toluene, a polymeric product was obtained in a $38.9 \%$ yield after purification with preparative recycling GPC (run 1 in Table I). Although the GPC-estimated $M_{\mathrm{n}}$ (PMMA standards) was very low $\left[M_{\mathrm{n}}=\right.$ 490 , corresponding to degree of polymerization $(\mathrm{DP})=2.17$, based on MW for $\mathbf{1}^{\prime}$ (the repeating unit derived from 1) of 226.06], its ${ }^{1} \mathrm{H}$ NMR spectrum in Figure 1 exhibits very broad signals assignable to $\mathrm{Hs}$ in $\mathbf{1}^{\prime}$, which may suggest that the exact $M_{\mathrm{n}}$ would be higher than the GPC-estimated value. Elemental analysis of the product (C: $62.03 \%, \mathrm{H}: 4.59 \%, \mathrm{~N}: 0.53 \%$ ) indicates the presence of small amount of $\mathrm{N}$, which should be ascribed to the incorporation of azo group $(-\mathrm{N}=\mathrm{N}-)$ in the main chain via a mechanism proposed in our previous publication for the Pd-mediated polymerization of diazoketones. ${ }^{7}$ Assuming that all the $\mathrm{C}$ content is derived from $\mathbf{1}^{\prime}$, the composition $\left[\mathbf{1}^{\prime}\right] /$ $[-\mathrm{N}=\mathrm{N}-]$ was calculated to be 1.0:0.044 $([-\mathrm{N}=\mathrm{N}-]=4.2$ mol \%). These results can be expected from the low polymerizability of diazoketones without a $\mathrm{C}=\mathrm{C}$ at the $\alpha, \beta$-position of $\mathrm{C}=\mathrm{O}$ as we reported, ${ }^{7}$ and demonstrate that low molecular weight polymers having a pendant ferrocene on all the main chain carbon atoms can be prepared by the Pd-mediated polymerization of $\mathbf{1}$ (Scheme 2).

Then, copolymerization of 1 with diazoketones, $(E)$-1-diazo3-nonen-2-one 3 and (E)-1-diazo-4-phenyl-3-buten-2-one $\mathbf{4}$ was examined (runs 2-7, Table I). Compared to the aforementioned homopolymerization of $\mathbf{1}$, the GPC-estimated $M_{\mathrm{n}} \mathrm{s}$ of the products became higher with the increase of the relative feed ratio of the diazoketones $\mathbf{3}$ and $\mathbf{4}$, and the composition of the repeating units estimated from the peak intensity in their ${ }^{1} \mathrm{H}$ NMR roughly corresponded to the feed ratio. The azo group contents (mol \% of [-N=N-] unit) in composition determined from elemental analysis were listed for runs 3 and 7 in Table I. Compared to the value for homopolymer of 1 ( $4.2 \mathrm{~mol} \%)$, it became much higher in run $3(13.0 \mathrm{~mol} \%)$, indicating that the azo group content depends on the kind of diazoketone comonomer employed for the copolymerization. These results demonstrate that the copolymerization of $\mathbf{1}$ with other diazocarbonyl compounds can provide a method to give a new type of linear polymer with pendant ferrocene groups (Scheme 3 ). 
Table I. Pd-mediated copolymerization of diazoacetylferrocene 1 and 1,1'-bis(diazoacetyl)ferrocene 2 with diazoketones 3 and $\mathbf{4}^{\text {a }}$

\begin{tabular}{|c|c|c|c|c|c|c|c|c|}
\hline \multirow[b]{2}{*}{ run } & \multirow[b]{2}{*}{ M1 } & \multirow[b]{2}{*}{ M2 } & \multirow[b]{2}{*}{$\begin{array}{l}\text { feed ratio } \\
{[\mathrm{M} 1]:[\mathrm{M} 2]}\end{array}$} & \multirow[b]{2}{*}{$\begin{array}{l}\text { yield }^{b} \\
(\%)\end{array}$} & \multirow[b]{2}{*}{$M_{\mathrm{n}}{ }^{\mathrm{c}}$} & \multirow[b]{2}{*}{$M_{\mathrm{w}} / M_{\mathrm{n}}{ }^{\mathrm{c}}$} & \multicolumn{2}{|c|}{ composition } \\
\hline & & & & & & & $\begin{array}{c}{\left[\mathrm{M}^{\prime}{ }^{\prime}\right]:\left[\mathrm{M} 2^{\prime}\right]^{\mathrm{d}}} \\
(\mathrm{NMR})\end{array}$ & $\begin{array}{c}{[-\mathrm{N}=\mathrm{N}-] \mathrm{mol} \% \mathrm{e}} \\
(\mathrm{EA})\end{array}$ \\
\hline 1 & 1 & - & $1: 0$ & 38.9 & 490 & 1.47 & - & $4.2 \%$ \\
\hline 2 & 1 & 3 & $3: 1$ & 45.7 & 650 & 1.42 & 1.9:1 & \\
\hline 3 & 1 & 3 & $1: 1$ & 26.3 & 1180 & 1.81 & $1: 1.6$ & $13.0 \%$ \\
\hline 4 & 1 & 3 & $1: 3$ & 24.0 & 1920 & 2.37 & $1: 4.6$ & \\
\hline 5 & 1 & 4 & $3: 1$ & 44.3 & 750 & 1.23 & 2.0:1 & \\
\hline 6 & 1 & 4 & $1: 1$ & 54.8 & 880 & 1.70 & $1: 1.3$ & \\
\hline 7 & 1 & 4 & $1: 3$ & 47.1 & 1130 & 1.66 & $1: 3.9$ & $3.3 \%$ \\
\hline 8 & 2 & 3 & $5: 1$ & 20.9 & 1940 & 2.88 & $3.4: 1$ & \\
\hline 9 & 2 & 3 & $3: 1$ & 23.0 & insolub & & $1.7: 1$ & \\
\hline 10 & 2 & 3 & $1: 1$ & 11.2 & insolub & & 1.3:1 & \\
\hline 11 & 2 & 3 & $1: 3$ & 10.3 & 2580 & 1.67 & $1: 1.9$ & $15.5 \%$ \\
\hline 12 & 2 & 4 & $5: 1$ & 35.9 & 770 & 2.03 & $2.5: 1$ & \\
\hline 13 & 2 & 4 & $3: 1$ & 41.0 & 1390 & 2.34 & $2.2: 1$ & \\
\hline 14 & 2 & 4 & $1: 1$ & 14.6 & 2740 & 3.40 & $1: 1.0$ & \\
\hline 15 & 2 & 4 & $1: 3$ & 28.7 & 1660 & 2.84 & $1: 1.9$ & $10.1 \%$ \\
\hline
\end{tabular}

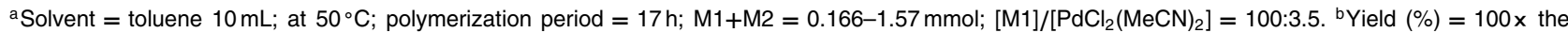
weight of the product after purification with the recycling GPC/(the weight of monomers-the weight of $\mathrm{N}$ contained in monomers). ${ }^{c} M_{\mathrm{n}}$ and $M_{\mathrm{w}} / M_{\mathrm{n}}$ were obtained by GPC calibration using standard PMMAs in THF solutions. ${ }^{\mathrm{d}} \mathrm{M} 1$ ' = repeating unit derived from $1 .{ }^{\mathrm{e}} \mathrm{The}$ mol\% of $-\mathrm{N}=\mathrm{N}$ - in the copolymer was calculated on the assumption that all the $\mathrm{C}$ content from $\mathrm{EA}$ derives from the repeating unit of monomers, without considering the polymer chain ends.

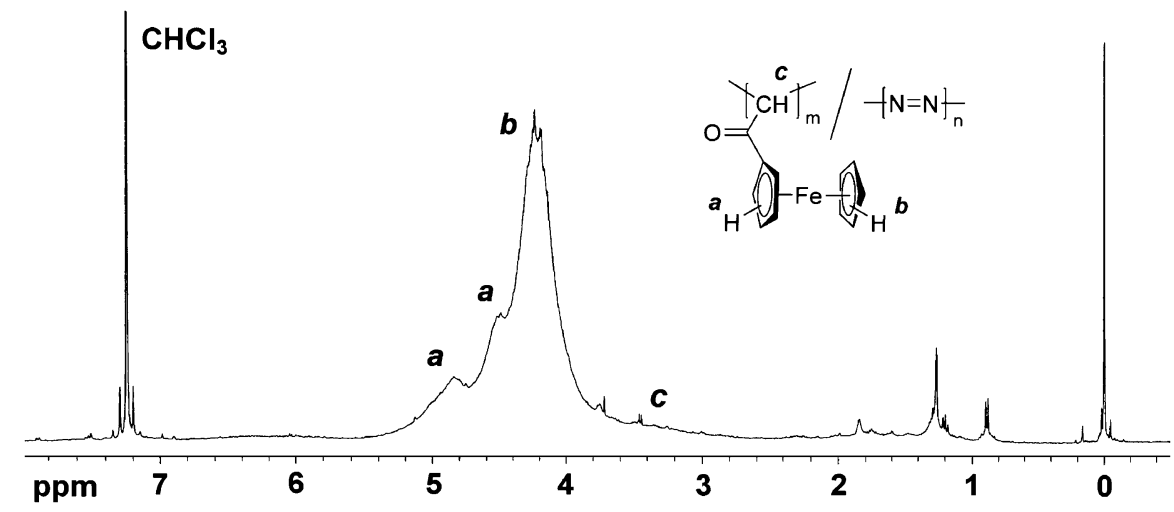

Figure 1. ${ }^{1} \mathrm{H}$ NMR spectrum of a product of Pd-mediated polymerization of diazoacetylferrocene 1 (run 1 in Table I).

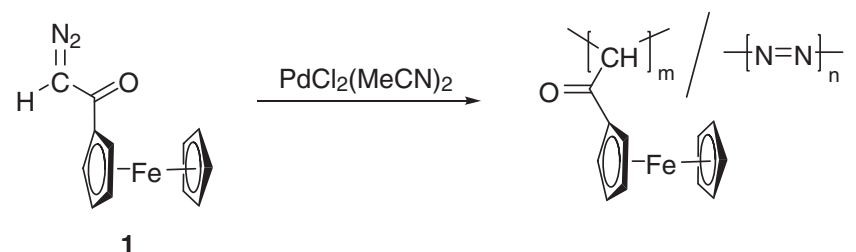

Scheme 2. Pd-mediated polymerization of diazoacetylferrocene 1.

As we confirmed the reactivity of the diazoacetyl group attached to ferrocene with $\mathrm{PdCl}_{2}(\mathrm{MeCN})_{2}$, Pd-mediated copolymerization of $1,1^{\prime}$-bis(diazoacetyl)ferrocene 2 with the diazoketones $\mathbf{3}$ and $\mathbf{4}$ was investigated (Scheme 4) and the results are summarized in runs $8-15$ in Table I. Contrary to our expectation of the formation of crosslinked polymers, the residues obtained after removal of volatiles from the reaction mixtures in these copolymerizations were soluble in $\mathrm{CHCl}_{3}$,

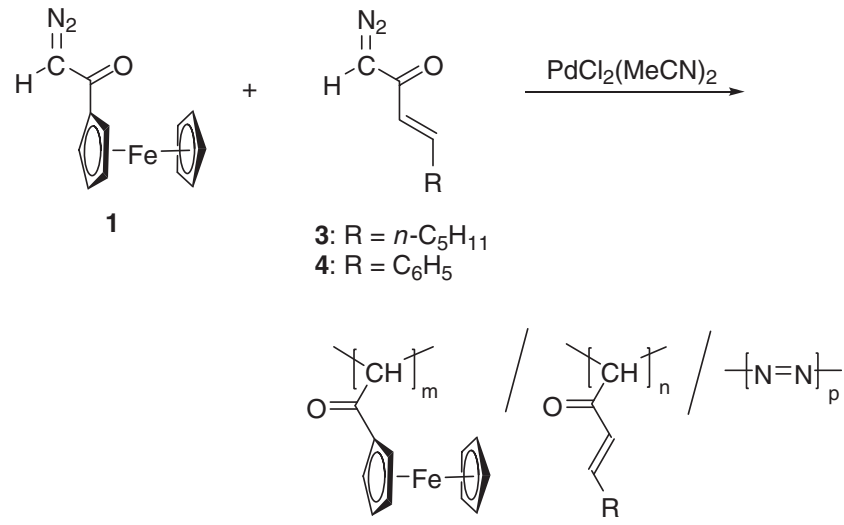

Scheme 3. Copolymerization of diazoacetylferrocene $\mathbf{1}$ with diazoketones 3 and 4. 


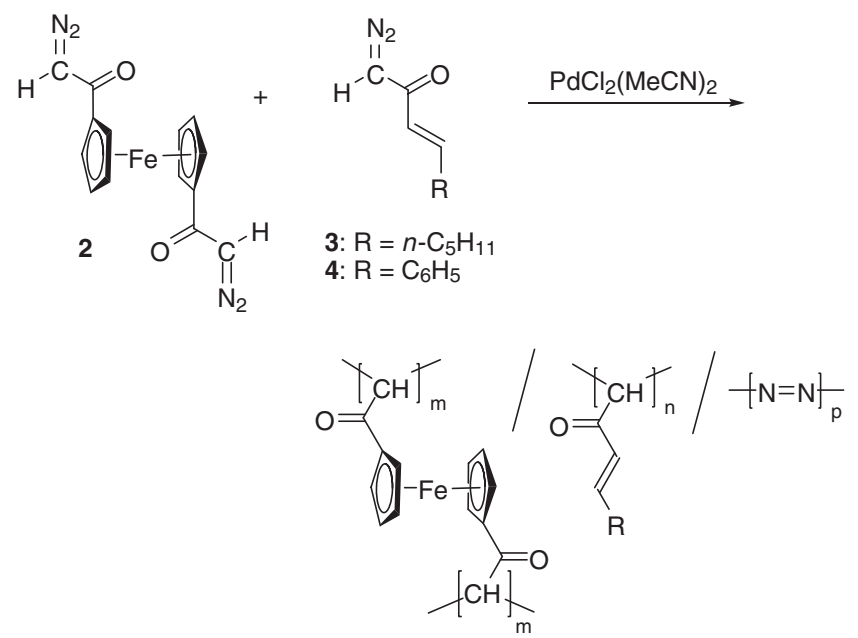

Scheme 4. Copolymerization of diazoacetylferrocene 2 with diazoketones 3 and 4.

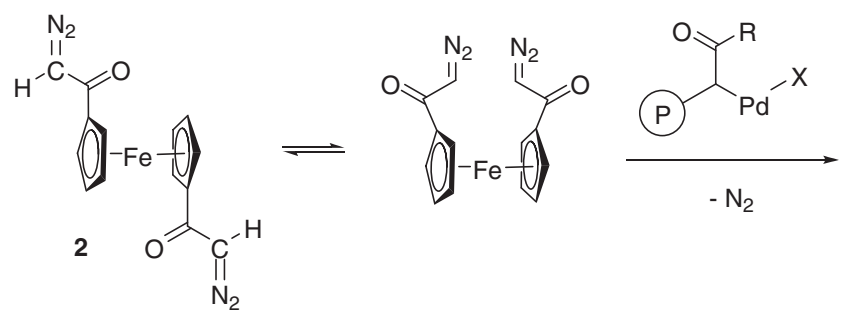

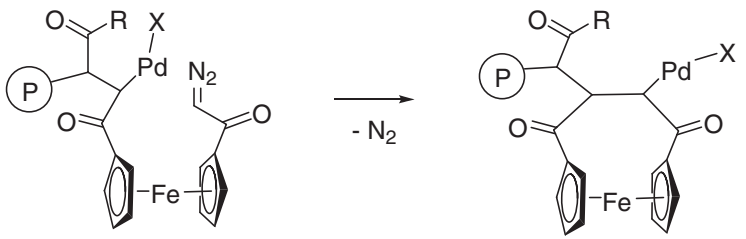

$\mathrm{X}=\mathrm{Cl}$ or growing polymer chain<smiles>CCC/C=C/C(=O)C(C)C(C)C</smiles>

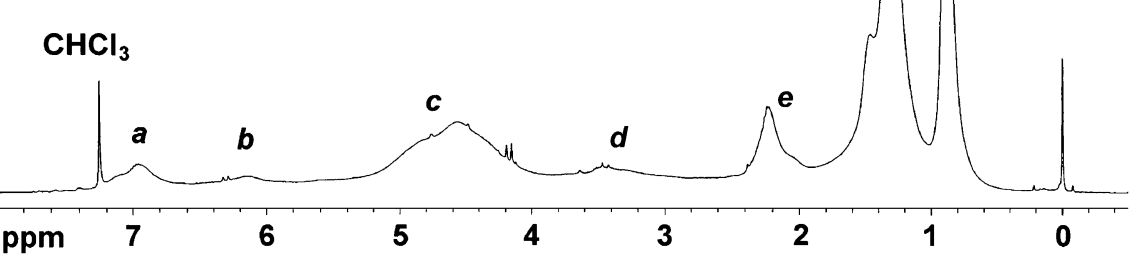

Figure 2. ${ }^{1} \mathrm{H}$ NMR spectrum for poly $\left(\mathbf{2}^{\prime}-c o-\mathbf{3}^{\prime}\right)$ (run 11 in Table I).

whereas the products obtained in runs 9 and 10 were insoluble in THF. In addition, GPC-estimated $M_{\mathrm{n}} \mathrm{s}$ for the THF-soluble products are rather low and nearly equal to the $M_{\mathrm{n}} \mathrm{s}$ for polymers obtained from the Pd-mediated homopolymerization of $\mathbf{3}$ and $4{ }^{7}$ indicating that the efficiency of the crosslinking is considerably low even if both diazoacetyl groups in $\mathbf{2}$ reacted. The compositions of the products were estimated from their ${ }^{1} \mathrm{H} \mathrm{NMR}$ spectra in $\mathrm{CDCl}_{3}$, whose example for run 11 is shown in Figure 2, and the compositions estimated from the signal intensities roughly corresponded to the feed ratio. We assume that one possible reason for the inefficient crosslinking would be intramolecular cyclization of two diazo groups in $\mathbf{2}$. As illustrated in Scheme 5, because of the free rotation of $\mathrm{Cp}$ rings attached to the $\mathrm{Fe}$ center, the successive reaction of two diazoacetyl units in a same molecule would occur favorably, resulting in the formation of a predominantly linear polymer with a very small number of branches at most, although we do not have any direct evidence for the occurrence of the cyclization. As listed in Table I, the presence of azo groups was indicated for the sample in runs 11 and 15 by elemental analyses, and the contents was again dependent on the kind of diazoketone comonomers.
Pd-mediated Copolymerization of Bis(diazoacetyl) Compounds with Diazoketones and Diazoacetate

From the results described above, it becomes clear that we need to use bifunctional diazocarbonyl compounds in which the intramolecular cyclization is not possible, for the effective formation of crosslinked polymers. As such compounds, we designed 4,4'-bis(diazoacetyl)biphenyl 5 and bis(4-diazoacetylphenyl)dimethylsilane $\mathbf{6}$, whose preparation from the corresponding diacetyl precursors is described in Scheme 6.

The Pd-mediated copolymerization of $\mathbf{5}$ with diazoketone $\mathbf{3}$ and ethyl diazoacetate 7 was examined, and the results are summarized in Table II, where THF was used as a solvent because of the low solubility of $\mathbf{5}$ in toluene. As shown in runs 1-3, when a mixture of $\mathbf{3}$ and $\mathbf{5}$ was reacted with $\mathrm{PdCl}_{2}(\mathrm{MeCN})_{2}$ in $\mathrm{THF}$ at $50^{\circ} \mathrm{C}$ with the total monomer concentration of $0.1 \mathrm{M}$ ([total monomer] $/[\mathrm{Pd}]=50$ ), we obtained polymeric products soluble in $\mathrm{CHCl}_{3}$, whose ${ }^{1} \mathrm{H}$ NMR spectra exhibited broad signals assignable to $\mathrm{Hs}$ in the repeating units from $\mathbf{3}$ and $\mathbf{5}$. Both the $\mathbf{3}^{\prime}$ content in the composition determined from relative peak intensities in ${ }^{1} \mathrm{H}$ NMR and GPC-estimated $M_{\mathrm{n}}$ increased with the increase of the feed ratio of 3 . In particular, the $M_{\mathrm{n}}$ of 11500 in run 3 is 


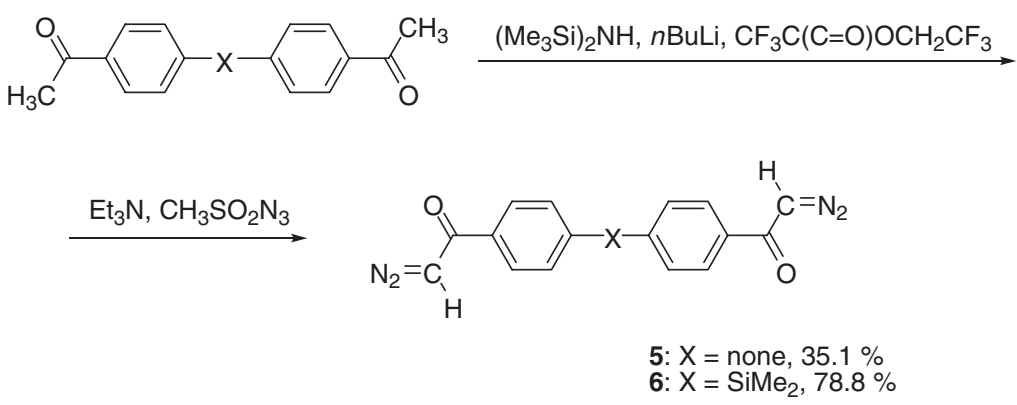

Scheme 6. Syntheses of bis(diazoacetyl) compounds 5 and $\mathbf{6}$.

Table II. Pd-mediated copolymerization of 4,4'-bis(diazoacetyl)biphenyl 5 with diazoketones 3 and ethyl diazoacetate $\mathbf{7}^{\text {a }}$

\begin{tabular}{|c|c|c|c|c|c|c|c|c|}
\hline \multirow[b]{2}{*}{ run } & \multirow[b]{2}{*}{$\begin{array}{c}3 \text { or } 7 \\
(\mathrm{M} 2)\end{array}$} & \multirow{2}{*}{$\begin{array}{c}\text { feed ratio } \\
{[5]:[\mathrm{M} 2]}\end{array}$} & \multirow[b]{2}{*}{$\begin{array}{c}{[5]+[\mathrm{M} 2]} \\
(\mathrm{M})\end{array}$} & \multirow{2}{*}{$\begin{array}{l}\text { yield }^{b} \\
(\%)\end{array}$} & \multirow[b]{2}{*}{$M_{\mathrm{n}}^{\mathrm{c}}$} & \multirow[b]{2}{*}{$M_{\mathrm{w}} / M_{\mathrm{n}}{ }^{\mathrm{c}}$} & \multicolumn{2}{|c|}{ composition } \\
\hline & & & & & & & $\begin{array}{c}{\left[5^{\prime}\right]:\left[\mathrm{M}^{\prime}\right]^{\mathrm{d}}} \\
(\mathrm{NMR})\end{array}$ & $\begin{array}{c}{[-\mathrm{N}=\mathrm{N}-] \mathrm{mol} \% \mathrm{e}} \\
(E A)\end{array}$ \\
\hline 1 & 3 & $1: 10$ & 0.1 & 27.3 & 4690 & 2.09 & $1: 5.7$ & \\
\hline 2 & 3 & $1: 5$ & 0.1 & 36.3 & 7000 & 4.19 & $1: 3.4$ & \\
\hline 3 & 3 & $1: 3$ & 0.1 & 36.1 & 11500 & 1.62 & $1: 3.1$ & \\
\hline 4 & 3 & $1: 1$ & 0.1 & 96.2 & \multicolumn{2}{|c|}{ insoluble in $\mathrm{CHCl}_{3}$} & & \\
\hline 5 & 3 & $1: 7$ & 0.2 & 67.8 & 2180 & 2.16 & $1: 6.4$ & \\
\hline 6 & 3 & $1: 5$ & 0.2 & 55.1 & 50400 & 1.49 & $1: 4.1$ & $3.6 \%$ \\
\hline 7 & 3 & $1: 3$ & 0.2 & 95.8 & \multicolumn{2}{|c|}{ insoluble in $\mathrm{CHCl}_{3}$} & & \\
\hline 8 & 7 & $1: 7$ & 0.2 & 56.2 & 3350 & 3.40 & $1: 4.1$ & $0 \%$ \\
\hline 9 & 7 & $1: 5$ & 0.2 & 30.0 & 12100 & 2.91 & $1: 3.1$ & \\
\hline 10 & 7 & $1: 3$ & 0.2 & 89.8 & \multicolumn{2}{|c|}{ insoluble in $\mathrm{CHCl}_{3}$} & & \\
\hline
\end{tabular}

a Solvent $=$ THF $5-12 \mathrm{~mL}$; at $50^{\circ} \mathrm{C}$; polymerization period $=17 \mathrm{~h} ;([5]+[\mathrm{M} 2]) /\left[\mathrm{PdCl}_{2}(\mathrm{MeCN})_{2}\right]=50: 1$. ${ }^{\text {b }}$ Yield $(\%)=100 \times$ the weight of the product after purification with the recycling GPC/(the weight of monomers- the weight of N contained in monomers). ${ }^{c} M_{\mathrm{n}}$ and $M_{\mathrm{w}} / M_{\mathrm{n}}$ were obtained by GPC calibration using standard PMMAs in THF solutions. ${ }^{\mathrm{d}} 5^{\prime}=$ repeating unit derived from 5 . ${ }^{\mathrm{e}}$ The $\mathrm{mol} \%$ of $-\mathrm{N}=\mathrm{N}$ - in the copolymer was calculated on the assumption that all the $\mathrm{C}$ content from EA derives from the repeating unit of monomers, without considering the polymer chain ends.

much higher than that observed in the Pd-mediated homopolymerization of $\mathbf{3}$ under a similar condition $\left(M_{\mathrm{n}}=c a\right.$. 2000). Furthermore, the copolymerization with a feed ratio [5]/[3] of $1: 1$ in run 4 afforded an insoluble product in an almost quantitative yield. These results indicate that, in contrast to $\mathbf{2}$, biphenyl-bridged bis(diazoacetyl) compounds $\mathbf{5}$ effectively acts as a crosslinking agent in the copolymerization as we expected (Scheme 7). The much higher yield of insoluble products could be ascribed to more effective incorporation of monomers into the crosslinked framework with relatively high feed ratios of bifunctional monomers, compared to that in the formation of linear polymers.

Expecting higher crosslinking efficiency, we conducted the copolymerization in a higher total monomer concentration of $0.2 \mathrm{M}$ (runs 5-7). As expected, under the condition, a product insoluble in $\mathrm{CHCl}_{3}$ was obtained in a high yield with the lower relative feed ratio of $[5] /[3]=1: 3$ (run 7 ) than that required in the case for total monomer concentration of $0.1 \mathrm{M}$ in run 4 $([5] /[3]=1: 1)$. Interesting to note is that a high molecular weight soluble product with GPC-estimated $M_{\mathrm{n}}=50400$ was obtained in the feed ratio of $[5] /[3]=1 / 5$ (run 6). In a similar manner, the copolymerization of $\mathbf{5}$ with diazoacetate $\mathbf{7}$ was examined, where high molecular weight soluble products or a

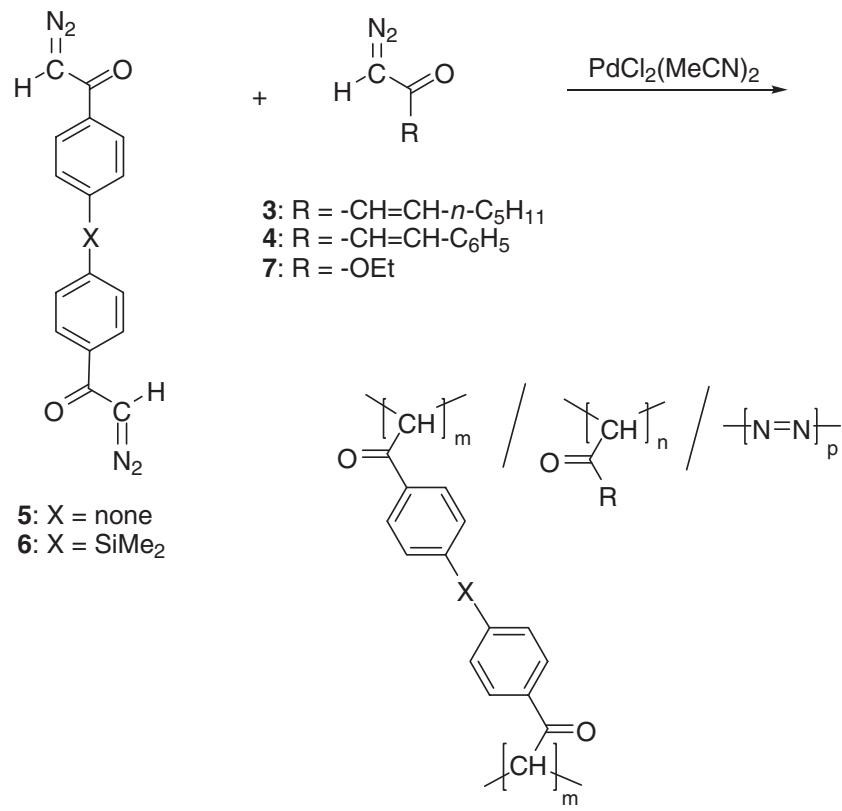

Scheme 7. Copolymerization of bis(diazoacetyl) compounds 5 and 6 with diazoketones $\mathbf{3}$ and $\mathbf{4}$ and ethyle diazoacetate $\mathbf{7}$. 
Table III. Pd-mediated copolymerization of bis(4-diazoacetylphenyl)dimethylsilane 6 with diazoketones 3, 4 and ethyl diazoacetate $\mathbf{7}^{\text {a }}$

\begin{tabular}{|c|c|c|c|c|c|c|c|c|}
\hline \multirow[b]{2}{*}{ run } & \multirow{2}{*}{$\begin{array}{c}3,4 \text {, or } 7 \\
(\mathrm{M} 2)\end{array}$} & \multirow{2}{*}{$\begin{array}{c}\text { feed ratio } \\
{[6]:[\mathrm{M} 2]}\end{array}$} & \multirow{2}{*}{$\begin{array}{l}\text { yield }^{\mathrm{b}} \\
(\%)\end{array}$} & \multirow[b]{2}{*}{$M_{\mathrm{n}}^{\mathrm{c}}$} & \multirow[b]{2}{*}{$M_{\mathrm{w}} / M_{\mathrm{n}}{ }^{\mathrm{c}}$} & \multicolumn{2}{|c|}{ composition } & \multirow{2}{*}{$\frac{T_{\mathrm{d} 10}}{\left({ }^{\circ} \mathrm{C}\right)}$} \\
\hline & & & & & & $\begin{array}{l}{\left[6^{\prime}\right]:\left[\mathrm{M} 2^{\prime}\right]^{d}} \\
(\mathrm{NMR})\end{array}$ & $\begin{array}{c}{[-\mathrm{N}=\mathrm{N}-] \mathrm{mol} \% \mathrm{e}} \\
(\mathrm{EA})\end{array}$ & \\
\hline 1 & 3 & $1: 5$ & 47.8 & 7100 & 1.98 & $1: 1.7$ & $5.2 \%$ & 268 \\
\hline 2 & 3 & $1: 3$ & 64.2 & \multicolumn{2}{|c|}{ insoluble in $\mathrm{CHCl}_{3}$} & & & 255 \\
\hline 3 & 4 & $1: 5$ & 67.5 & 2280 & 5.46 & $1: 3.1$ & $0 \%$ & 236 \\
\hline 4 & 4 & $1: 3$ & 39.9 & 7000 & 7.42 & $1: 1.4$ & & 216 \\
\hline 5 & 4 & $1: 2$ & 96.1 & \multicolumn{2}{|c|}{ insoluble in $\mathrm{CHCl}_{3}$} & & & 243 \\
\hline 6 & 7 & $1: 5$ & 31.7 & 1500 & 2.27 & $1: 4.0$ & & 195 \\
\hline 7 & 7 & $1: 3$ & 46.4 & 1810 & 4.29 & $1: 3.0$ & $3.4 \%$ & 193 \\
\hline 8 & 7 & $1: 2$ & 44.7 & 2560 & 4.10 & $1: 3.3$ & & 229 \\
\hline 9 & 7 & $1: 1$ & 68.7 & \multicolumn{2}{|c|}{ insoluble in $\mathrm{CHCl}_{3}$} & & & 223 \\
\hline
\end{tabular}

a Solvent $=$ toluene $3.0-7.3 \mathrm{~mL}$; at $50^{\circ} \mathrm{C}$; polymerization period $=17 \mathrm{~h}$; $([6]+[\mathrm{M} 2]) /\left[\mathrm{PdCl}_{2}\left(\mathrm{MeCN}_{2}\right]=50: 1\right.$. b Yield $(\%)=100 \times$ the weight of the product after purification with the recycling GPC/(the weight of monomers-the weight of $\mathrm{N}$ contained in monomers). ${ }^{\mathrm{c}} M_{\mathrm{n}}$ and $M_{\mathrm{w}} / M_{\mathrm{n}}$ were obtained by GPC calibration using standard PMMAs in THF solutions. ${ }^{\mathrm{d}} \mathbf{6}^{\prime}=$ repeating unit derived from $\mathbf{6}$. ${ }^{\mathrm{e}}$ The $\mathrm{mol} \%$ of $-\mathrm{N}=\mathrm{N}$ - in the copolymer was calculated on the assumption that all the $\mathrm{C}$ content from EA derives from the repeating unit of monomers, without considering the polymer chain ends.

crosslinked insoluble product were obtained depending on the feed ratio of [5]/[7] (runs 8-10). The mol \% values of azo group $(-\mathrm{N}=\mathrm{N}-)$ listed for runs 6 and 8 show that the content is rather low in these comonomer combinations. These results demonstrate that crosslinked polymers can actually be prepared by employing appropriate bifunctional diazocarbonyl compounds, in an analogous manner as copolymerization of styrene with divinylbenzene.

Finally, $\mathrm{Me}_{2} \mathrm{Si}$-bridged bis(diazoacetylphenyl) compound $\mathbf{6}$, which is soluble in toluene, was employed as a bifunctional monomer. As summarized in Table III, the Pd-mediated copolymerization of $\mathbf{6}$ with $\mathbf{3}, \mathbf{4}$, and $\mathbf{7}$ afforded insoluble products with feed ratios of $[\mathbf{6}] /[\mathbf{3}, \mathbf{4}$, or $\mathbf{7}]=1: 3,1: 2$, and $1: 1$, respectively, in good yields. Soluble products obtained with lower relative feed ratio of $\mathbf{6}$ exhibited signals expected for both repeating units in their ${ }^{1} \mathrm{H}$ NMR spectra, whereas the $M_{\mathrm{n}} \mathrm{s}$ of these copolymers are lower than those of the soluble products obtained in Table II. The azo content in these copolymers revealed by elemental analyses are rather low as listed in Table III.

In order to check the effect of crosslinking, $10 \%$ decomposition temperature $\left(T_{\mathrm{d} 10}\right)$ for the copolymers were measured by using thermogravimetric analysis (TGA), and the values were listed in Table III. Compared to the $T_{\mathrm{d} 10}$ for homopolymers derived from $3\left(220^{\circ} \mathrm{C}\right), \mathbf{4}\left(232^{\circ} \mathrm{C}\right)$, and $7\left(183^{\circ} \mathrm{C}\right)$, the decomposition temperature apparently raised in most cases, which could be ascribed to the effect of crosslinking on thermal stability.

\section{CONCLUSIONS}

We have demonstrated that it is really possible to obtain crosslinked polymers from Pd-mediated copolymerization of bi- and monofunctional diazocarbonyl compounds. The density of substitutent in each lattice in the network of the products should be higher than that of network polymers prepared by vinyl polymerization using bifunctional comonomers, such as copolymerization of styrene with divinylbenzene. The copoly- merization would be a general method for the synthesis of a new type of network polymer, which could be utilized as functional materials in the future.

Acknowledgment. This research was supported by the Grants-in-Aid for Scientific Research (B) (No. 18350066) from Japan Society for the Promotion of Science (JSPS).

Received: July 21, 2009 Accepted: August 24, 2009 Published: October 9, 2009

\section{REFERENCES AND NOTES}

1. L. Liu, Y. Song, and H. Li, Polym. Int., 51, 1047 (2002).

2. E. Ihara, N. Haida, M. Iio, and K. Inoue, Macromolecules, 36, 36 (2003).

3. D. G. H. Hetterscheid, C. Hendriksen, W. I. Dzik, J. M. M. Smits, E. R. H. van Eck, A. E. Rowan, V. Busico, M. Vacatello, V. Van Axel Castelli, A. Segre, E. Jellema, T. G. Bloemberg, and B. de Bruin, J. Am. Chem. Soc., 128, 9746 (2006).

4. E. Jellema, P. H. M. Budzelaar, J. N. H. Reek, and B. de Bruin, J. Am. Chem. Soc., 129, 11631 (2007).

5. J. Bai, L. D. Burke, and K. J. Shea, J. Am. Chem. Soc., 129, 4981 (2007).

6. Z. Zhang and J. Wang, Tetrahedron, 64, 6577 (2008).

7. E. Ihara, M. Fujioka, N. Haida, T. Itoh, and K. Inoue, Macromolecules, 38, 2101 (2005).

8. E. Ihara, T. Hiraren, T. Itoh, and K. Inoue, J. Polym. Sci., Part A: Polym. Chem., 46, 1638 (2008).

9. E. Ihara, T. Hiraren, T. Itoh, and K. Inoue, Polym. J., 40, 1094 (2008).

10. A. Aguilar-Aguilar, A. D. Allen, E. P. Cabrera, A. Fedorov, N. Fu, H. Henry-Riyad, J. Leuninger, U. Schmid, T. T. Tidwell, and R. Verma, J. Org. Chem., 70, 9556 (2005).

11. V. I. Sokolov, T. V. Potolokova, M. N. Nefedova, and A. S. Peregudov, Russ. Chem. Bull., 52, 1452 (2003).

12. S. Itsuno and K. Komura, Tetrahedron, 58, 8237 (2002).

13. R. L. Danheiser, R. F. Miller, R. G. Brisbois, and S. Z. Park, J. Org. Chem., 55, 1959 (1990).

14. N. E. Searle, in "Organic Synthesis Collective," N. Rabjohn, Ed., John Wiley and Sons, 1963, Vol. 4, pp 424-426.

15. L. S. Hegedus, in "Organometallics in Synthesis. A Manual," M. Schlosser, Ed., John Wiley \& Sons, 2002, p 1126. 